Gynecologic and

Obstetric Investigation
Gynecol Obstet Invest 2014;77:245-249

DOI: $10.1159 / 000358877$
Received: July 22, 2013

Accepted after revision: January 20, 2014 Published online: March 7, 2014

\title{
Vaginal Lactoferrin Administration before Genetic Amniocentesis Decreases Amniotic Interleukin-6 Levels
}

\author{
Fortunato Vesce $^{a}$ Emilio Giugliano $^{a}$ Stefania Bignardi ${ }^{a}$ Elisa Cagnazzo ${ }^{a}$ \\ Cecilia Colamussi $^{a}$ Roberto Marci ${ }^{a}$ Nicoletta Valente ${ }^{b}$ Silvia Seraceni ${ }^{b}$ \\ Martina Maritati $^{\mathrm{b}}$ Carlo Contini $^{\mathrm{b}}$ \\ aSection of Obstetrics and Gynecology, Department of Morphology, Surgery and Experimental Medicine, and \\ bSection of Infectious Diseases, Department of Medical Sciences, University of Ferrara, Ferrara, Italy
}

\section{Key Words}

Amniocentesis · Abortion · Interleukin-6 · Lactoferrin

\section{Abstract}

Aim: To verify the eventual efficacy of lactoferrin (LF), an iron-binding glycoprotein, to decrease the amniotic concentration of interleukin-6 (IL-6). Methods: We prospectively enrolled 60 Caucasian patients at the 16th week of their singleton physiological gestation. A vaginal compound containing $300 \mathrm{mg}$ of LF was administered randomly 4 or $12 \mathrm{~h}$ prior to amniocentesis, as to obtain 3 groups: A, 20 untreated patients; B, 20 treated $4 \mathrm{~h}$ before amniocentesis; $\mathrm{C}$, 20 treated $12 \mathrm{~h}$ before amniocentesis. Results: A normal karyotype was registered in all cases. The comparison of the distribution of IL- 6 among the 3 groups showed a highly significant difference $(p=0.001)$. The difference between mean values of group $B$ and both groups $C$ and $A$ was shown to be highly significant ( $p=0.006$ and $p=0.03$, respectively). In contrast, there was no significant difference between mean values of groups A and C. Conclusion: Vaginal LF administration decreases amniotic IL-6 concentration. We therefore suggest that the glycoprotein may exert a protective role against ominous pregnancy complications linked to an increased level of the cytokine, such as abortion secondary to amniocentesis.

(c) 2014 S. Karger AG, Basel

\section{Introduction}

Adverse outcomes of pregnancy, such as abortion and premature delivery, are a consequence of cytokine imbalance. Therefore, in obstetrics special interest arouse concerning interleukin-6 (IL-6), an activator of acute phase responses and a lymphocyte stimulator, that over the years has been assigned both pro- and anti-inflammatory characteristics $[1,2]$. Indeed, an increased amniotic fluid (AF) IL-6 concentration was reported in patients with pregnancy loss following second trimester amniocentesis [3], and the same correlation was subsequently confirmed for preterm delivery and fetal growth restriction $[4,5]$, thus suggesting that reducing the cytokine level might improve the outcome of pregnancy by rebalancing the

\section{KARGER}

E-Mail karger@karger.com

www.karger.com/goi
(C) 2014 S. Karger AG, Basel

0378-7346/14/0774-0245\$39.50/0
Fortunato Vesce

University of Ferrara

Corso Giovecca 183

IT-44121 Ferrara (Italy)

E-Mail ves@unife.it 
inflammatory response. In this regard, we have shown that ampicillin is able to decrease Il-6 release by WHISH cells, a human amnion-derived cell line, as well as the AF cytokine concentration in women undergoing second trimester amniocentesis [6]. In the present study we focused on lactoferrin (LF), an 80-kDa iron-binding glycoprotein of the transferrin family provided with anti-inflammatory and antimicrobial properties, which is able to decrease IL-6 in several experimental conditions [7]. LF is physiologically present in AF $[8,9]$, and it is frequently administered to pregnant women for treating iron deficiency anemia [10].

Considering the safety of the drug administration during pregnancy, its eventual efficacy to decrease AF IL-6 could represent a useful tool in preventing abortion secondary to amniocentesis.

\section{Methods}

We performed an open-label clinical study enrolling 60 Caucasian pregnant patients undergoing genetic amniocentesis at the 16th gestational week at the Obstetric Unit of Ferrara University from March 2011 to March 2012. The inclusion criteria were: singleton physiological pregnancy and maternal age as the only indication to fetal karyotyping. The exclusion criteria were: consumption of drugs interfering with the immune system, previous miscarriages, pregnancy at risk for maternal or fetal disease, lactose intolerance. The research was in accordance with the ethical principles of the Declaration of Helsinki. The Local Ethics Committee approved the study design. All pregnant women gave their written informed consent. A vaginal compound containing $300 \mathrm{mg}$ of LF (Difesan, Progine Farmaceutici, Firenze, Italy) was randomly administered to patients 4 or $12 \mathrm{~h}$ prior to amniocentesis, in order to obtain 3 groups:

- group A: 20 untreated patients;

- group B: 20 patients treated $4 \mathrm{~h}$ before amniocentesis;

- group C: 20 patients treated $12 \mathrm{~h}$ before amniocentesis.

A total amount of $20 \mathrm{ml} \mathrm{AF}$ was withdrawn for karyotype analysis, microbiological culture, $\alpha$-fetoprotein $(18 \mathrm{ml})$ and IL- 6 assay $(2 \mathrm{ml})$.

Our protocol entails using 22-gauge needles provided with a 24-gauge tip, in order to reduce the diameter of the hole in the amniotic membrane and the consequent risk of AF leakage.

A questionnaire was administered to the patients, in order to check for any complication (vaginal bleeding, uterine contraction, rupture of the membranes) within 7 days following the procedure.

Immunoassay for IL-6 in AF Specimens

Fresh AF specimens $(2 \mathrm{ml})$ were centrifuged at $3,000 \mathrm{~g}, 4^{\circ} \mathrm{C}$ for $10 \mathrm{~min}$. The proinflammatory cytokine IL- 6 was measured and quantified in the AF supernatants $(100 \mu \mathrm{l})$, aliquoted and stored at $-70^{\circ} \mathrm{C}$ until analysis, by an enzyme-linked immunoabsorbent assay using a Quantikine Elisa Human IL-6 Kit (R \& R Systems, Minneapolis, Minn., USA), according to the manufacturer's instructions. For all assays, full or diluted (1:10 to 1:100) AF samples (test-

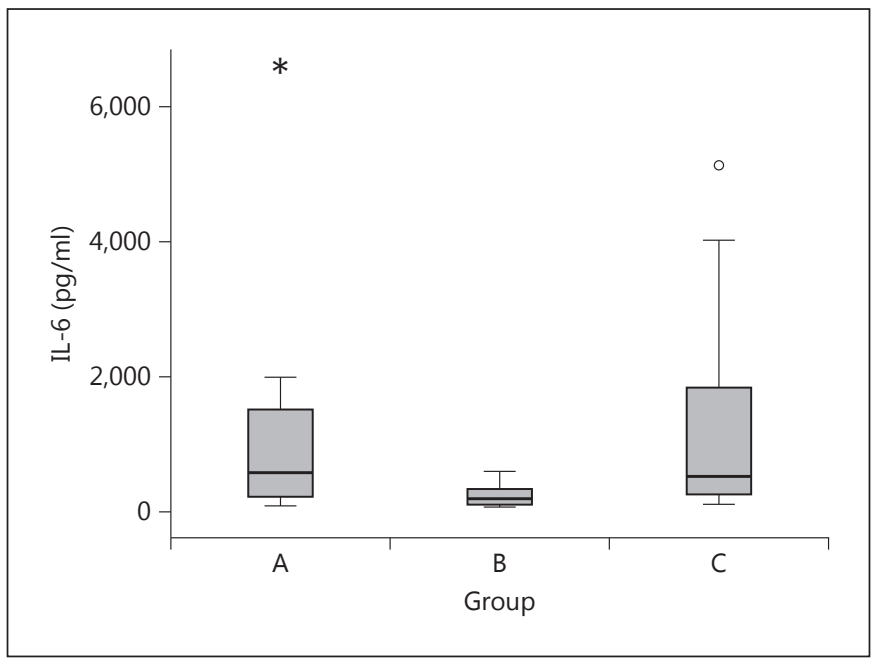

Fig. 1. Graphical representation (box-and-whiskers plot) of the distribution of IL- 6 among the 3 groups.

ed in duplicates) were done to fall within the range of the standard curves as previously described [11]. The interassay and intra-assay coefficients of variation were $<10 \%$ for all the analytes. The lower detection limit for human IL-6 was $3.12 \mathrm{pg} / \mathrm{ml}$. A zero value was assigned to samples below these limits.

\section{Statistical Analysis}

Data were analyzed using SPSS, version 20.0 (SPSS Inc., Chicago, Ill., USA). Nonparametric analysis by the Kruskal-Wallis test was considered appropriate for the sample size. The Behrens-Fisher test was used to verify the difference among mean IL-6 values in the 3 groups. Differences with $\mathrm{p}<0.05$ were considered statistically significant.

\section{Results}

The mean maternal age in the whole study population was $37.5 \pm 2.1$ years (minimum 35 , maximum 42 ). This parameter was not different among the 3 groups $(\mathrm{p}=0.5)$ and distributed as follows: $37.8( \pm 2.4), 37.7( \pm 2.3)$ and $37.1( \pm 2.1)$ years, respectively, for groups A, B and C.

A normal karyotype was registered in all cases. The AF microbiological cultures were negative in all the samples. No complication (vaginal bleeding, uterine contractions and ruptured membranes) was registered within 7 days after amniocentesis. The course of pregnancy was normal in all patients, ending in spontaneous delivery at term.

The comparison of the distribution of the IL- 6 values among the 3 groups showed a highly significant difference $(p=0.001)$. Significance was further confirmed by the Behrens-Fisher test. In particular, the IL- 6 group B 
Table 1. Post hoc control by Behrens-Fisher test to compare IL-6 values among the 3 groups

\begin{tabular}{|c|c|c|c|}
\hline Group & IL-6 value, $\mathrm{pg} / \mathrm{ml}$ & $\begin{array}{l}95 \% \text { confidence } \\
\text { interval }\end{array}$ & $\mathrm{p}$ value \\
\hline A vs. B & $\begin{array}{l}1,084.1( \pm 1,458.3) \\
\text { vs. } \\
\quad 242.3( \pm 163.5)\end{array}$ & 81.8 to $1,601.8$ & 0.03 \\
\hline A vs. C & $\begin{array}{l}1,084.1( \pm 1,458.3) \\
\text { vs. } \\
1,315.7( \pm 1,472.2)\end{array}$ & -991.6 to 528.3 & 0.5 \\
\hline B vs. C & $\begin{array}{l}\quad 242.3( \pm 163.5) \\
\text { vs. } \\
1,315.7( \pm 1,472.2)\end{array}$ & $-1,833.4$ to -313.5 & 0.006 \\
\hline
\end{tabular}

mean value was shown to be significantly lower compared with those of the other two groups, with a significance of $p=0.006$ and $p=0.03$ compared with groups $C$ and $A$, respectively. In contrast, there was no significant difference between group A and group C IL-6 mean values (table 1).

These differences are graphically represented in figure 1 , where value distribution shows a particularly narrow box-and-whiskers plot width in group B compared with the other two.

\section{Discussion}

It is well known that some of the cytokines involved in the inflammatory response also regulate implantation and labor. Indeed, an inflammatory microenvironment appears to be required for adequate tissue remodeling during the early phase of physiological pregnancy [12]. In contrast, the second trimester, along with a large part of the third, is characterized by the prevalence of anti-inflammatory signals. Again the scale plate hangs down towards an inflammatory pattern near term, for inducing uterine contractions and cervical dilatation [13]. Therefore, it can be argued that cytokines and prostanoids are not inflammatory by themselves, as in normal conditions such compounds do regulate important physiological functions. It is rather their imbalance that triggers inflammation [14]. Ominous complications of the second and third trimesters are related to an increased level of cytokines able to induce prostanoid release, thus triggering uterine contraction and impairing uteroplacental blood flow. Either abortion or premature delivery has been re-

Vaginal Lactoferrin before Genetic

Amniocentesis lated to increased inflammatory and decreased anti-inflammatory cytokines. Such changes are frequently ascribed to bacterial mediation $[15,16]$, but an increased IL- 6 concentration in the fetal compartment (AF and fetal blood) plays itself a relevant role even in the absence of any evidence of infection [17]; accordingly, it has been shown to predict abortion secondary to amniocentesis [3]. The mechanism by which the cytokine is able to directly trigger uterine contractions appears to be the activation of the arachidonic acid cascade, with consequent production of prostaglandin $\mathrm{E}_{2}$ [18-20]. As for possible causes other than infection for an increased release of cytokines able to trigger gestational inflammation, it has been shown that genetic proinflammatory cytokine polymorphisms are associated with a higher risk of preterm birth [21-24]. Whatever the cause, IL-6 elevation cannot be considered to be a benign state [25], suggesting a search for suitable therapies aimed at reducing its concentration, in order to prevent dangerous prostaglandin release. Accordingly, anticytokine therapy has recently been suggested for preterm labor as well [26]. As mentioned above, ampicillin is able to directly inhibit amniotic IL-6 release both in vitro and in women undergoing genetic amniocentesis [6]. Furthermore, the drug significantly decreases basal as well as stimulated prostaglandin $\mathrm{E}_{2}$ release from amnion tissue [27] while other classes of antibiotics not only lack this ability, but also impair that of ampicillin when administered together [28]. Based on the evidence above, and considering that the $1.4 \%$ abortion rate following amniocentesis [29] might at least in part derive from a preexistent inflammatory gestational condition (whether or not related to infection), we felt it was justified to administer ampicillin to all women undergoing invasive prenatal diagnostic procedures. We started this strategy many years ago, and our total abortion rate for genetic amniocentesis is $0.3 \%$, i.e. below the natural incidence observed between 16 and 24 weeks. Other authors suggest a different approach for preventing abortion secondary to amniocentesis [30]. Indeed, considering that the intrauterine environment might not be sterile, they tested the capacity of a macrolide antibiotic in reducing the abortion rate following the procedure. Their study is quite remarkable due to the extremely high number of cases, although it raises concern as regards some of the data. For instance, in spite of quoting a 1.08 natural abortion rate [31] following amniocentesis, the authors reported only a $0.28 \%$ incidence in the control group, compared with $0.03 \%$ in treated patients. In other words, it appears that, in their hands, the invasive procedure in itself was provided with a protective efficacy against preg- 
nancy loss, a quality hard to recognize even for highly skilled operators! Apart from such a questionable datum, further doubts arise from considering that, although macrolides provide protection against sensitive germs, they are not only unable to directly decrease amniotic prostaglandin release, but also their addition completely abolishes this capability of ampicillin [28]. Therefore, given the dual action of ampicillin against IL- 6 and prostaglandin $\mathrm{E}_{2}$, along with the broad spectrum bactericide efficacy, one wonders why the large trial mentioned above tested a macrolide instead!

However, waiting for the question to be answered, it seems also appropriate to search for less harmful drugs compared to antibiotics, provided with the same protective efficacy, along with a decreased risk of side effects. This was the purpose of the present study, testing the efficacy of vaginal administration of LF in decreasing the amniotic concentration of IL- 6 in women undergoing genetic amniocentesis.

LF is a major component of the mammalian innate immune system. Its protective effects range from direct antimicrobial activities against a large panel of microorganisms, including bacteria, viruses, fungi and parasites, to anti-inflammatory and anticancer action. These activities rely upon LF capable of binding iron as well as the protein interactions with molecular and cellular components of both host and pathogens $[32,33]$. Interestingly, endogenous AF LF normally increases after 31 weeks of gestation. However, levels above $2.5 \mu \mathrm{g} / \mathrm{ml}$ before this gestational age are considered highly suggestive of intra-amniotic infections [34, 35], thus indicating that endogenous LF release represents a natural protective response of the organism.

Moreover, the exogenous bovine form, administered for treating iron deficiency anemia, has been reported to decrease IL-6 concentration in the maternal serum [7].

With the aim to counteract the inflammatory cascade triggered by the tissue lesion that an invasive diagnostic procedure produces even in expert hands, in the present study we tested the efficacy of exogenous LF, administered throughout the vaginal route to decrease the amniotic level of IL-6 in patients undergoing genetic amniocentesis. Our data show that $300 \mathrm{mg}$ of the compound significantly reduce the cytokine concentration as early as $4 \mathrm{~h}$ after administration. However, no significant difference is found between mean IL- 6 values after $12 \mathrm{~h}$ and those of the controls. Such a behavior is probably due to the short half-life of LF, and it represents a further expression of the effectiveness of the drug. Indeed, besides a short resistance to peptic degradation (about $17 \mathrm{~min}$ ), oral LF shows a very short half-life (about $8 \mathrm{~min}$ ) and a poor bioavailability [36]. It is noteworthy that along with the decrease in the values, their distribution becomes particularly narrow $4 \mathrm{~h}$ after LF administration, to widen and increase again with time, due to the short half-life of the drug. Therefore, the opportunity of several daily doses may be suggested in order to maintain a low level of the cytokine.

We consider such an action an interesting finding for a compound that is also a natural component of the human body, although we are aware that our study population was restricted to cases with a normal pregnancy. Whether or not the same result could be obtained in patients with inflammatory syndrome remains to be ascertained. On the other hand, we know that even the most experienced operator is unable to avoid the risk of abortion produced by tissue damage derived from invasive prenatal diagnosis. Evidence reported in the literature indicates that such a risk is likely of an inflammatory nature, and therefore it must be prevented by the administration of anti-inflammatory drugs. In this respect, besides ampicillin and cephalosporin that represent the best antibiotic choice, transvaginal LF could be a good alternative. In this regard, it will be necessary to ascertain whether, in addition to inhibiting amniotic IL-6 release, the compound also reduces prostaglandin $\mathrm{E}_{2}$ synthesis, thereby enhancing its effectiveness against abortion. If so, it would seem more appropriate to entrust the task of a general anti-inflammatory action to the natural compound, reserving the antibiotic for cases of infection.

In conclusion, in patients undergoing genetic amniocentesis, the capacity of transvaginal LF to decrease amniotic IL-6 levels may represent a useful tool against the increased risk of abortion that the procedure entails.

\footnotetext{
References

1 Xing Z, Gauldie J, Cox G, Baumann H, Jordana M, Lei XF, Achong MK: IL-6 is an antiinflammatory cytokine required for controlling local or systemic acute inflammatory responses. J Clin Invest 1998;101:311-320.

- 2 Hurst SM, Wilkinson TS, McLoughlin RM, Jones S, Horiuchi S, Yamamoto N, Rose-John S, Fuller GM, Topley N, Jones SA: Control of leukocyte infiltration during inflammation: IL-6 and its soluble receptor orchestrate a temporal switch in the pattern of leukocyte recruitment. Immunity 2001;14:705-714.

- 3 Wenstrom KD, Andrews WW, Tamura T, DuBard MB, Johnston KE, Hemstreet GP: Elevated amniotic fluid interleukin-6 levels at genetic amniocentesis predict subsequent pregnancy loss. Am J Obstet Gynecol 1996; 175:830-833.
} 
4 Bogavac M, Brkic S, Simin N, Celic D: Midpregnancy interleukin levels in serum and amniotic fluid as predictors of preterm delivery. J Matern Fetal Neonatal Med 2012, Epub ahead of print.

5 Xiao JP, Yin YX, Gao YF, Lau S, Shen F, Zhao $M$, Chen $Q$ : The increased maternal serum levels of IL-6 are associated with the severity and onset of preeclampsia. Cytokine 2012;60: 856-860.

6 Vesce F, Pavan B, Lunghi L, Giovannini G, Scapoli C, Piffanelli A, Biondi C: Inhibition of amniotic interleukin- 6 and prostaglandin $\mathrm{E}_{2}$ release by ampicillin. Obstet Gynecol 2004; 103:108-113.

7 Paesano R, Berlutti F, Pietropaoli M, Goolsbee W, Pacifici E, Valenti P: Lactoferrin efficacy versus ferrous sulfate in curing iron disorders in pregnant and non-pregnant women. Int J Immunopathol Pharmacol 2010;23: 577-587.

$>8$ Levay PF, Viljoen M: Lactoferrin: a general review. Haematologica 1995;80:252-267.

>9 Niemela A, Kulomaa M, Vilja P, Tuohimaa P, Saarikoski S: Lactoferrin in human amniotic fluid. Hum Reprod 1989;4:99-101.

-10 Nappi C, Tommaselli GA, Morra I, Massaro M, Formisano C, Di Carlo C: Efficacy and tolerability of oral bovine lactoferrin compared to ferrous sulfate in pregnant women with iron deficiency anemia: a prospective controlled randomized study. Acta Obstet Gynecol Scand 2009;88:1031-1035.

$>11$ Lee SY, Buhimschi IA, Dulay AT, Ali UA, Zhao G, Abdel-Razeq SS, Bahtiyar MO, Thung SF, Funai EF, Buhimschi CS: IL-6 trans-signaling system in intra-amniotic inflammation, preterm birth, and preterm premature rupture of the membranes. J Immunol 2011;186:3226-3236.

-12 Challis JR, Lockwood CJ, Myatt L, Norman JE, Strauss JF 3rd, Petraglia F: Inflammation and pregnancy. Reprod Sci 2009;16:206-215.

$\checkmark 13$ Paulesu L, Bhattacharjee J, Bechi N, Romagnoli R, Jantra S, Ietta F: Pro-inflammatory cytokines in animal and human gestation. Curr Pharm Des 2010;16:3601-3615.

-14 Lunghi L, Pavan B, Biondi C, Paolillo R, Valerio A, Vesce F, Patella A: Use of glucocorticoids in pregnancy. Curr Pharm Des 2010;16: 3616-3637.
15 Suzuki Y, Yamamoto T, Kojima K, Tanemura M, Tateyama H, Suzumori K: Evaluation of levels of cytokines in amniotic fluid of women with intrauterine infection in the early second trimester. Fetal Diagn Ther 2006;21:45-50.

16 Dudley DJ: Pre-term labor: an intra-uterine inflammatory response syndrome? J Reprod Immunol 1997;36:93-109.

17 Goldenberg RL, Culhane JF, Iams JD, Romero R: Epidemiology and causes of preterm birth. Lancet 2008;371:75-84.

18 Romero R, Gomez R, Ghezzi F, Yoon BH, Mazor M, Edwin SS, Berry SM: A fetal systemic inflammatory response is followed by the spontaneous onset of preterm parturition. Am J Obstet Gynecol 1998;179:186-193.

19 Akira S, Taga T, Kishimoto T: Interleukin-6 in biology and medicine. Adv Immunol 1993; 54:1-78.

20 Lee SE, Romero R, Park CW, Jun JK, Yoon $\mathrm{BH}$ : The frequency and significance of intraamniotic inflammation in patients with cervical insufficiency. Am J Obstet Gynecol 2008; 198:633.

21 Engel SA, Erichsen HC, Savitz DA, Thorp J, Chanock SJ, Olshan AF: Risk of spontaneous preterm birth is associated with common proinflammatory cytokine polymorphisms. Epidemiology 2005;16:469-477.

22 Holst D, Garnier Y: Preterm birth and inflammation - the role of genetic polymorphisms. Eur J Obstet Gynecol Reprod Biol 2008;141: 3-9.

23 Annells MF, Hart PH, Mullighan CG, Heatley SL, Robinson JS, McDonald HM: Polymorphisms in immunoregulatory genes and the risk of histologic chorioamnionitis in Caucasoid women: a case control study. BMC Pregnancy Childbirth 2005;5:4.

24 Song C, Xie S, Wang J, Lian J, Diao B, Tang Y: Association of angiotensinogen gene polymorphisms and angiogenic factors with preeclampsia in Chinese women. Gynecol Obstet Invest 2013;76:64-68.

25 Gomez R, Romero R, Ghezzi F, Yoon BH, Mazor M, Berry SM: The fetal inflammatory response syndrome. Am J Obstet Gynecol 1998;179:194-202.

26 Sado T, Kitanaka T, Naruse K, Oi H, Noguchi T, Yoshida S, Kajihara H, Shigetomi H, Oonogi A, Kobayashi $\mathrm{H}$ : Anticytokine therapy in preterm labor: current knowledge and future perspectives. Gynecol Obstet Invest 2011;71: $1-10$.
27 Vesce F, Buzzi M, Ferretti ME, Pavan B, Bianciotto A, Jorizzo G, Biondi C: Inhibition of amniotic prostaglandin E release by ampicillin. Am J Obstet Gynecol 1998;178:759-764.

28 Vesce F, Pavan B, Buzzi M, Pareschi MC, Bianciotto A, Iorizzo G, Biondi C: Effect of different classes of antibiotics on amniotic prostaglandin E release. Prostaglandins Other Lipid Mediat 1999;57:207-218.

$\checkmark 29$ Tabor A, Vestergaard CH, Lidegaard Ø: Fetal loss rate after chorionic villus sampling and amniocentesis: an 11-year national registry study. Ultrasound Obstet Gynecol 2009;34: 19-24.

30 Giorlandino C, Cignini P, Cini M, Brizzi C, Carcioppolo O, Milite V, Coco C, Gentili P, Mangiafico L, Mesoraca A, Bizzoco D, Gabrielli I, Mobili L: Antibiotic prophylaxis before second-trimester genetic amniocentesis (APGA): a single-centre open randomised controlled trial. Prenat Diagn 2009;29:606612.

31 Seeds JW: Diagnostic mid trimester amniocentesis: how safe? Am J Obstet Gynecol 2004; 191:607-615.

32 González-Chávez SA, Arévalo-Gallegos S, Rascón-Cruz Q: Lactoferrin: structure, function and applications. Int $\mathrm{J}$ Antimicrob Agents 2009;33:301

33 Actor JK, Hwang SA, Kruzel ML: Lactoferrin as a natural immune modulator. Curr Pharm Des 2009;15:1956-1973.

-34 Otsuki K, Yoda A, Toma Y, Shimizu Y, Saito $\mathrm{H}$, Yanaihara T: Lactoferrin and interleukin-6 interaction in amniotic infection. Adv Exp Med Biol 1998;443:267-271.

>35 Heller KA, Greig PC, Heine RP: Amnioticfluid lactoferrin: a marker for subclinical intra-amniotic infection prior to 32 weeks gestation. Infect Dis Obstet Gynecol 1995;3:179_ 183.

36 Nojima Y, Suzuki Y, Yoshida K, Abe F, Shiga T, Takeuchi T, Sugiyama A, Shimizu H, Sato A: Lactoferrin conjugated with $40-\mathrm{kDa}$ branched poly(ethylene glycol) has an improved circulating half-life. Pharm Res 2009; 26:2125-2132.
Vaginal Lactoferrin before Genetic Amniocentesis
Gynecol Obstet Invest 2014;77:245-249 DOI: $10.1159 / 000358877$ 